\title{
Characteristics of Thyroid Cancer Patients in Haji Adam Malik General Hospital
}

\author{
Rizka Annisa Harahap ${ }^{1}$, Pimpin Utama Pohan ${ }^{2 *}$, Sufitni ${ }^{3}$ \\ ${ }^{1}$ Medical Faculty, University of Sumatera Utara, Medan, Indonesia \\ ${ }^{2}$ Department of Surgery, Division of Surgical Oncology, Medical Faculty, University of Sumatera Utara, Medan, Indonesia \\ ${ }^{3}$ Department of Anatomy, Medical Faculty, University of Sumatera Utara, Medan, Indonesia
}

\section{ARTICLE INFO}

Received : 13 June 2020

Reviewed : 07 August 2020

Accepted : 21 May 2021

\section{Keywords:}

patients characteristics, thyroid cancer

\begin{abstract}
Methods: This is a cross-sectional study and carried out among 97 patients with thyroid cancer at Haji Adam Malik General Hospital from 2013 until 2015. Secondary data were obtained by consecutive sampling techniques using medical records. The inclusion criteria are all patients diagnosed with thyroid cancer based on histopathological analysis. Data were analyzed descriptively using SPSS in percentage.
\end{abstract}

Results: From 97 patients with thyroid cancer, it could be concluded that thyroid cancer is the most frequently diagnosed in the age group of 55-64 years (32.0\%). Females were predominant that attributed to $71.1 \%$ than males (28.9\%). The majority of thyroid cancer was diagnosed at stage IV (39.2\%) with the most common histopathological feature of papillary thyroid carcinoma $(46,4 \%)$. Thyroid cancer patients are usually found with normal BMI $(37.1 \%)$ and nodule thyroid found with the diameter of $\geq 4 \mathrm{~cm}(47.4 \%)$.

Conclusions: In the 55-64-year age female group, thyroid cancer is most diagnosed at stage IV with papillary thyroid carcinoma. Thyroid cancer patients are usually found with normal BMI and the nodule size of $\geq 4 \mathrm{~cm}$.

\begin{abstract}
Background: Thyroid cancer is the most common endocrine cancer, and its incidence has continuously increased in the last three decades all over the world. The national prevalence of thyroid cancer has not been recorded. Sex, obesity, and the size of thyroid nodules are the risk factors for thyroid cancer. The aim of this study is to acknowledge the characteristics of thyroid cancer patients in Haji Adam Malik General Hospital.
\end{abstract}

\author{
*Corresponding author: \\ Pimpin Utama Pohan \\ Department of Surgery, Division of \\ Surgical Oncology, Medical Faculty, \\ University of Sumatera Utara, Medan, \\ Indonesia \\ pimpin19782002@yahoo.com
}

\section{INTRODUCTION}

Thyroid cancer is one of the most malignant endocrine tumors. The incidence in the world continues to increase over the last three decades. It is estimated that $1.0 \%-1.5 \%$ of all new cancer cases diagnosed in the United States is thyroid cancer [1]. The prevalence of thyroid cancer nationally has not been obtained yet. This cancer ranks 8th out of all malignancies that occur throughout the body based on the new cases that occurred in 2016. There are an estimated 64,300 new cases that occurred in 2016 (3.8\% of all cancer incidents). The number of new cases of thyroid cancer is 13.9 per 100,000 every year. This cancer is most often diagnosed at the age of 45-54 years with an average age of 50 [2].
Thyroid cancer is also affected by race/ethnicity and gender. On the whole race, thyroid cancer is more common in women, which is about four times more than in men. In general, thyroid cancer is common in the east part of the world including Asia. The incidence of thyroid cancer in Asian women is 22.7 per 100,000 every year, while in Asian men 9.7 per 100,000 every year [2].

Various things can be a risk factor for thyroid cancer, such as obesity. Some studies reported that obesity is a risk factor for thyroid cancer; the percentage of thyroid cancer is higher in obese patients compared to nonobese patients (30\% vs $22 \%$ ) [4,5].

Thyroid cancer is classified into four types based on histopathological features, which are papillary thyroid carcinoma, follicular thyroid carcinoma, medullary 
thyroid carcinoma, and anaplastic thyroid carcinoma. Approximately $85 \%$ of all thyroid cancers are papillary thyroid carcinoma followed by follicular (11\%), medullary (3-5\%), and anaplastic (2-5\%) [6].

There is no data on the characteristics of thyroid cancer in Haji Adam Malik General Hospital until now, especially in the distribution of body mass index (BMI) and thyroid nodules. Thus, this study was conducted to describe the characteristics of thyroid cancer in the Haji Adam Malik General Hospital from 2013 to 2015. The study could present the specific characteristics of Asian thyroid cancer patients, especially BMI and thyroid nodules. Further studies can be done to analyze the association of BMI and thyroid nodules with thyroid cancer.

\section{METHODS}

A cross-sectional study was carried out among 97 patients with thyroid cancer at Haji Adam Malik General Hospital from 2013 to 2015. Secondary data with consecutive sampling techniques were used in this study using medical records from Haji Adam Malik General Hospital. The inclusion criteria are all patients diagnosed with thyroid cancer based on the histopathological analysis.

Age was classified into several groups as follows: $<20$ years until $>84$ years. Sex information was classified as male and female. Histopathological features of thyroid cancer were based on National Cancer Institute such as: papillary, follicular, medullary, and anaplastic. The staging of thyroid cancer was divided into four (I-IV) based on AJCC (2010). Body mass index (BMI) was classified into several categories based on the Asia Pacific BMI classification. Thyroid nodule size was divide into four groups, $1.0 \mathrm{~cm}$ until $>4.0 \mathrm{~cm}$. Data were analyzed descriptively using the Statistical Package of Social Service (SPSS) version 23.0 in percentage.

This research had received permission from the Health Research Ethical Committee of the Medical Faculty of Universitas Sumatera Utara/H. Adam Malik General Hospital, with letter number 39/080816/KEPK FK USU-RSUP HAM/2016.

\section{RESULTS}

There were 97 eligible samples enrolled in this study from 2013 to 2015 at Haji Adam Malik General Hospital. Table 1 shows the frequency distribution based on the patient's clinical characteristics as follows.
Table 1. Comparison of characteristics of thyroid cancer patients based on gender

\begin{tabular}{|c|c|c|c|c|}
\hline & \multicolumn{2}{|c|}{ Female } & \multicolumn{2}{|c|}{ Male } \\
\hline & $\mathbf{n}$ & $\%$ & $\mathbf{n}$ & $\%$ \\
\hline \multicolumn{5}{|l|}{ Age } \\
\hline$<20$ years & 1 & 1.4 & 0 & 0.0 \\
\hline 20-34 years & 12 & 16.9 & 2 & 7.7 \\
\hline $35-44$ years & 12 & 16.9 & 2 & 7.7 \\
\hline $45-54$ years & 18 & 25.4 & 9 & 34.6 \\
\hline $55-64$ years & 22 & 31.0 & 9 & 34.6 \\
\hline $65-74$ years & 5 & 7.0 & 3 & 11.6 \\
\hline $75-84$ years & 1 & 1.4 & 1 & 3.8 \\
\hline \multicolumn{5}{|l|}{ Clinical stage } \\
\hline Stage I & 19 & 27.6 & 4 & 14.3 \\
\hline Stage II & 9 & 13.0 & 3 & 10.7 \\
\hline Stage III & 16 & 23.2 & 8 & 28.6 \\
\hline Stage IV & 25 & 36.2 & 13 & 46.4 \\
\hline \multicolumn{5}{|c|}{ Histopathological description } \\
\hline Papillary & 29 & 42.0 & 16 & 57.1 \\
\hline Follicular & 32 & 46.4 & 6 & 21.4 \\
\hline Medullary & 2 & 2.9 & 1 & 3.6 \\
\hline Anaplastic & 6 & 8.7 & 5 & 17.9 \\
\hline \multicolumn{5}{|l|}{ Years of diagnose } \\
\hline 2013 & 20 & 28.2 & 6 & 23.1 \\
\hline 2014 & 23 & 32.4 & 8 & 30.7 \\
\hline 2015 & 28 & 39.4 & 12 & 46.2 \\
\hline \multicolumn{5}{|l|}{ Body mass index } \\
\hline Underweight & 7 & 10.2 & 2 & 7.1 \\
\hline Normal & 23 & 33.3 & 13 & 46.4 \\
\hline Pre-obese & 20 & 29.0 & 3 & 10.7 \\
\hline Obesity grade I & 15 & 21.7 & 6 & 21.5 \\
\hline Obesity grade II & 4 & 5.8 & 4 & 14.3 \\
\hline \multicolumn{5}{|l|}{ Nodule size } \\
\hline $1.0-1.9 \mathrm{~cm}$ & 12 & 17.7 & 3 & 10.3 \\
\hline $2.0-2.9 \mathrm{~cm}$ & 10 & 14.7 & 6 & 20.7 \\
\hline $3.0-3.9 \mathrm{~cm}$ & 13 & 19.1 & 7 & 24.1 \\
\hline$>3.9 \mathrm{~cm}$ & 33 & 48.5 & 13 & 44.9 \\
\hline
\end{tabular}

Based on Table 1, it can be concluded that the highest number of people affected by thyroid carcinoma in female was found in the age group of 55-64 years (31.0\%) followed by the age group of $45-54$ years 
(25.4\%) and male in the age group of 45-54 years $(34.6 \%)$. Both males and females are most diagnosed at stage IV about $46.4 \%$ and $36.2 \%$. Based on the histological features of thyroid cancer in female, we found that follicular thyroid carcinoma was more common than other types (about $46.4 \%$ ) followed by papillary thyroid carcinoma $(42.0 \%)$, anaplastic thyroid carcinoma $(8.7 \%)$, and medullary thyroid carcinoma (2.9\%) while in male, papillary thyroid carcinoma was more common than other types (about 57.1\%) followed by follicular thyroid carcinoma (21.4\%), anaplastic thyroid carcinoma (17.9\%), and medullary thyroid carcinoma $(1.0 \%)$. Medullary thyroid carcinoma is the rarest type found in both genders.

From 2013 until 2015, we can see an increase in thyroid cancer cases both in males and females each year. The highest prevalence of thyroid cancer was found in normo-weight patients both in female (33.3\%) and male $(46.4 \%)$ followed by pre-obese patients in female $(29.0 \%)$ and obesity grade I in male (21.5\%). The same as the prevalence in thyroid cancer was found in patients with the nodule size of $>3.9 \mathrm{~cm}$ both in male (44.4\%) and female $(48.5 \%)$ followed by patients with the nodule size of $3.0-3.9 \mathrm{~cm}$ both in female (19.1\%) and male (24.1\%).

\section{DISCUSSION}

The highest prevalence of thyroid cancer was found in the age groups of $55-64$ years (32\%) and $45-54$ years (27.8\%). A study conducted by Lukas et al. [6] found that the highest number of people affected by thyroid carcinoma was found in the age group of 55-59 years $(12.2 \%)$. The second highest case was found in the age group of 60-64 years old (12.0\%) with an average of 53 years. Something similar was also reported by Goyal et al. [7] that most thyroid carcinoma cases were diagnosed at the age of 65 years on average. This statement is based on the finding in thyroid cancer prevalence that is higher in elders in line with malignant cells aggressiveness and the metastasis risk which are also found higher [8].

Based on this study, it can be concluded that females are 2.5 times more affected than males. Some studies found that thyroid cancer affected females 8-10 times higher than males due to the difference of their estrogen levels. National Cancer Institute also explained that thyroid cancer in the Asian race is mostly found in women, about 22.7 per 100.000 women every year compared to men, 9.7 per 100,000 . Besides, in the American Indian race, there are 14.5 per 100,000 women every year compared to men 3.9 per 100,000 every year [9].

Histology types of thyroid cancer are classified into four types, papillary thyroid carcinoma, follicular thyroid carcinoma, medullary thyroid carcinoma, and anaplastic thyroid carcinoma. Based on this study, we conclude that the most common type of thyroid cancer found in the sample is papillary (about $46.4 \%$ ) followed by follicular (39.2\%), anaplastic (11.3\%), and medullary (3.1\%). Something similar was reported by Pacini et al. [10] that the most common type of thyroid cancer was papillary with an incidence rate of about 5.7 per 100,000 every year, followed by follicular about 0.82 per 100,000 every year. Meanwhile, medullary and anaplastic types have the lowest incidence rates about 0.11 and 0.21 per 100,000 every year.

The most common type of thyroid cancer is papillary followed by follicular both types are derived from follicular cells that are dominating the thyroid gland. Meanwhile, medullary types are derived from parafollicular cells, and anaplastic types occur from other types of thyroid cancer which are treated properly [8]. A study conducted by Davies et al. [11] assumes that this is due to the increased number of accidental findings of thyroid cancer in small nodule size $(<1 \mathrm{~cm})$ while doing an early detection, which is an early stage of papillary microcarcinomas.

In general, thyroid cancer is mostly diagnosed the late stage. This is due to asymptomatic clinical manifestation in thyroid cancer, which tends to reveal the diagnosis unpurposely while doing physical examination or radiology examination at the late stage [12]. From this study, we found a high number of thyroid cancers in stage IV (about $39.2 \%$ ) followed by stage III $(24.7 \%)$ while the early stage is only $36.1 \%$ consisting of stage I $(23.7 \%)$ and stage II (12.4\%). This data shows a high number of advanced cases because the samples were taken in Haji Adam Malik General Hospital as Sumatera's referral center. A study conducted by Yoo et al. [13] found that most of the thyroid cancers were diagnosed unpurposely at the late stage $(54.8 \%)$ compared with purposely (13.5\%) [13]. A similar result has been found by a study conducted by Ganiasan at Haji Adam Malik General Hospital Medan in 2013 that most of the thyroid cancers were diagnosed at stage IV (42,6\%) [14].

A significant increase in the number of thyroid cancers is influenced by several risk factors such as obesity. The incidence of thyroid cancer has been steadily growing with the increasing obesity in the world. Our study found different results of prevalence that the majority of thyroid cancers happen to non-obese patients with normal BMI (37.1\%) followed by obese patients (29.8\%) consisting of obesity I (21\%) and obesity II (8.2\%).

A study conducted by Kitahara et al. [15] found that $\mathrm{BMI}$ was correlated with thyroid cancer both in men and women, which is similar to this study. They found that the prevalence of thyroid cancer in women with normal BMI was at $39 \%$ followed by obese patients $(30 \%)$, pre-obese $(28 \%)$, and underweight (3\%). Different results from the study conducted by Renehan et al. [16] in a meta-analysis found that a greater BMI was 
strongly associated with the risk of thyroid cancer in men and women. Different results from a study conducted by Han et al. [4] showed that a higher prevalence of thyroid cancer was found in obese women but not related in men allowing speculation regarding hormone effects or the insufficiency of male cases analyzed as thyroid cancer incidence is higher in women [17]. It is likely that gender influences the association of obesity status with thyroid cancer. A similar association was reported in a European prospective study by Rinaldi et al. [18] who found the association of thyroid cancer risk with obesity was only in women.

There were several potential explanations for why obese individuals may have a higher risk of thyroid cancer. First, there is a clinical association between higher serum thyroid-stimulating hormone (TSH) levels and increased risk of malignancy in human thyroid nodules and advanced stage of the disease [19]. Some cross-sectional studies in euthyroid subjects demonstrated a positive association between serum TSH and BMI. Potential stimulators of TSH production, explaining the increase in TSH in obese patients, include hormonal mediators of adipose tissue, especially leptin $[17,19]$. Second, leptin levels were higher in thyroid cancer patients compared to healthy subjects in a case-control study. Leptin was also shown to enhance the migration of PTC cells [19]. Leptin acts as a neuroendocrine regulator of the hypothalamic-pituitary-thyroid axis by regulating the expression of $\mathrm{TRH}$ in the paraventricular nucleus; leptin secretion by adipose tissue will then be stimulated by TSH. Leptin may also affect deiodinases, activating the T4 to T3 conversion [17]. Third, insulin resistance, a common metabolic perturbation in obesity, may play a role in thyroid tumor growth, with insulin directly binding to insulin receptors or stimulating insulin-like growth factor, estrogen, or other hormones, such as TSH, to enhance the proliferation of thyroid cancer cells [19].

Estrogens are known to promote thyroid tumor growth, and this relationship has been taken as a possible biological explanation for the increased thyroid cancer risk in postmenopausal women observed in earlier studies. However, estrogen promotion of thyroid tumor growth is unlikely to explain. A greater BMI has also been linked with certain dietary behaviors, such as excess protein and carbohydrate intake, that have been found to increase thyroid cancer risk [20]. Low levels of physical activity have been linked with a higher BMI and increased risk of some cancers, but most studies showed little or no association of physical activity with thyroid cancer risk $[15,20]$.

The majority of patients with thyroid cancer were found with thyroid nodules where the nodule size is associated with a malignancy risk for thyroid cancer. From this study, all of the samples had thyroid nodules. Our study found that the highest malignancy of the thyroid gland was found in a diameter of $\geq 4 \mathrm{~cm}$ of nodule size (39.2\%) and rare in a diameter of 1.0-1.9 $\mathrm{cm}(15.5 \%)$. Based on the study conducted by Abraham et al. [21], thyroid carcinoma was found in patients with an asymptomatic thyroid nodule. Kamran et al. [22] reported a similar finding that a notable threshold effect is detected at $2.0 \mathrm{~cm}$. However, further growth beyond $2 \mathrm{~cm}$ no longer impacts malignant risk. They also found that $13 \%$ of all thyroid nodules are histopathologically malignant whereas $16.3 \%$ of nodules $3.0-3.9 \mathrm{~cm}$, followed by $\geq 4 \mathrm{~cm}(15.0 \%), 2.0-2.9 \mathrm{~cm}$ (13.5\%), and $1.0-1.9 \mathrm{~cm}(10.5 \%)$ are malignant [22]. A study conducted by Hakami et al. [23] has a similar conclusion that the increase in thyroid nodule size impacts cancer risk, which is nonlinear fashion. A threshold is detected at $2 \mathrm{~cm}$, and an extension beyond $2 \mathrm{~cm}$ does not influence cancer risk. Nevertheless, the risk of follicular carcinomas and other rare thyroid malignancies increases as nodules enlarge.

The minimum number of samples made in this study cannot represent all of the characteristics of thyroid cancer, and because this is a cross-sectional study, we still cannot interpret the correlation between BMI and nodule size with thyroid study. Further studies are needed to analyze the association of BMI and thyroid nodules with thyroid cancer.

\section{CONCLUSIONS}

The highest prevalence of people affected by thyroid carcinoma was found in the age group of 55-64 years (32\%), where females are 2.5 times more affected by thyroid cancer than males. Most thyroid cancer histopathological features found in the sample were papillary thyroid carcinoma (46.4\%), and the highest number of thyroid cancer was found in stage IV about 38 cases $(39.2 \%)$ in both genders. The highest number of people affected by thyroid carcinoma was found in patients with normal BMI (37.1\%) followed by obese patients $(29.8 \%)$, and the most common thyroid nodule size in the sample was $\geq 4 \mathrm{~cm}(39.2 \%)$.

\section{DECLARATIONS}

\section{Competing of Interest}

The authors declare no competing interest in this study

\section{Acknowledgment}

I wish to thank all my friends and my teacher for helping me complete this research. 


\section{REFERENCES}

1. Pellegriti G, Frasca F, Regalbuto C, et al. Worldwide increasing incidence of thyroid cancer: update on epidemiology and risk factors. J Cancer Epidemiol. 2013;2013:965212.

2. National Cancer Institute. SEER Stat Fact Sheets: Thyroid Cancer [Internet]. [Place unknown]: Bethesda; 2016 [cited 2016 April 18]. Available from: http:// seer.cancer.gov/csr/1975_2013/

3. Pappa T, Alevizaki M. Obesity and thyroid cancer: a clinical update. Thyroid. 2014;24(2):190-9.

4. Han JM, Kim TY, Jeon MJ, et al. Obesity is a risk factor for thyroid cancer in a large, ultrasonographically screened population. Euro J Endocrinol. 2013;168:87986.

5. Pearce EN. Obesity is associated with thyroid cancer risk in women. Clin Thyroidol. 2013;25:107-8.

6. Lukas J, Drabek J, Lukas D, et al. The epidemiology of thyroid cancer in the Czech Republic in comparison with other countries. Biomed Pap Med. 2013;157(3):266-75.

7. Goyal N, Camacho F, Mangano J, Goldenberg D. Thyroid cancer characteristics in the population surrounding Three Mile Island. Laryngoscope. 2012;122(6):1415-21.

8. Brady LW, Heilmann HP, Molls M, Nieder C. Head and Neck cancers. In: Decision Making in Radiation Oncology volume 1. German: Springer; 2011.p. 179203.

9. National Cancer Institute. SEER Stat Fact Sheets: Thyroid Cancer [Internet]. [Place unknown]: Bethesda; 2016 [cited 2016 November 7]. Available from: http://seer/cancer.gov/csr/1975_2013/

10. Pacini F, Castagna MG, Brilli L, Pentheroudakis G; ESMO Guidelines Working Group. Thyroid cancer: ESMO Clinical Practice Guidelines for diagnosis, treatment and follow-up. Ann Oncol. 2012;23 Suppl 7:vii110-9.

11. Davies L, Welch HG. Increasing incidence of thyroid cancer in the United States, 1973-2002. JAMA. 2006;295:2164-7
12. Bindman RS, Lebda P, Feldstein VA, et al. Risk of thyroid cancer based on thyroid ultrasound imaging characteristics results of a population-based study. JAMA Internal Med. 2013;173(19):1788-96.

13. Yoo F, Chaikhoutdinov I, Mitzner R, et al. Characteristic of incidentally discovered thyroid. JAMA Oto-Head \& Neck Surg. 2013;139(11):1181-6.

14. Ganiasan Z. Profil Kanker Tiroid di RSUP. Haji Adam Malik pada Januari 2010-Desember 2011 (skripsi). Medan: Universitas Sumatera Utara;2013.

15. Kitahara CM, Platz EA, Freeman LE, et al. Obesity and thyroid cancer risk among U.S. men and women: a pooled analysis of five prospective studies. Cancer Epidemiol Biomarkers Prev. 2011;20(3):464-72.

16. Renehan AG, Tyson $M$, Egger $M$, et al. Body-mass index and incidence of cancer: a systematic review and meta-analysis of prospective observational studies. Lancet. 2008;371(9612):569-78.

17. Marcello MA, Cunha LL, Batista FA, Ward LS. Obesity and thyroid cancer. Endocr Relat Cancer. 2012;21(5):T255-71.

18. Rinaldi S, Lise M, Clavel-Chapelon F, et al. Body size and risk of differentiated thyroid carcinomas: findings from the EPIC study. Int J Cancer. 2012;131:E1004-14.

19. Ma J, Huang M, Wang Li, et al. Obesity and risk of thyroid cancer: Evidence from a meta - analysis of 21 observational studies. Med Sci Monit. 2015;21:283-91.

20. Xu L, Port M, Landi S, et al. Obesity and the risk of papillary thyroid cancer: a pooled analysis of three case-control studies. Thyroid. 2014;24(6):966-74.

21. Abraham J, Gulley JL, Allegra CJ. Other Malignancies. In: Bethesda Handbook of Clinical Oncology. 2nd ed. Philadelphia: Lippincott Williams \& Wilkins; 2005.p. 455-61.

22. Kamran SC, Marqusee E, Kim MI, et al. Thyroid nodule size and prediction of cancer. J Clin endocrinol Metab. 2013;98(2):564-70.

23. Hakami HA, Alqahtani R, Alahmadi A, et al. Thyroid nodule size and predicion of cancer: a study at tertiary care hospital in Saudi Arabia. Cureus. 2020;12(3):1-11. 